\title{
A UMBANDA E A GLOCALIZAÇÃO
}

Steven Engler ${ }^{l}$

Resumo: Em face de certas pressuposições globalizantes da apropriação norteamericana da Afro-Brazilian religion, levanto uma pergunta hipotética: que diferença faria se - em vez do candomblé servir como o exemplo universal e transnacional do sincretismo religioso - a umbanda servisse como um exemplo do hibridismo cultural brasileiro? Sugiro a elaboração de um conceito específico - o 'hibridismo de refração' - no qual, o espectro de umbandas refrata o espectro de tensōes sociais na sociedade brasileira. Com referência à teoria recente da globalização, argumento que a variação interna da umbanda reflete uma variedade de apropriações estratégicas de conceitos e modelos nacionais e transnacionais. Isto afirma a autonomia contextualizada desses agentes religiosos brasileiros e necessita uma dimensão nacional em qualquer análise das tensões constitutivas desta espécie de glocalização.

Palavras-chave: Sincretismo; Hibridismo; Globalização; Glocalização; Tradição; Candomblé; Umbanda.

Abstract: This paper interrogates a particular globalizing academic move: the appropriation of Afro-Brazilian religion by the academic study of religion in North America as a paradigmatic form of cultural mixture. Specifically, I ask what difference would it make if Umbanda were the key example of Brazilian cultural hybridity, rather than Candomblé serving as a more universal example of religious syncretism. I elaborate the concept of hybridity of refraction, according to which the ritual and doctrinal spectrum of Umbandas refracts the spectrum of social tensions in Brazilian society. Referring to recent theories of globalization, I argue that Umbanda's internal variation manifests a variety of strategic appropriations by its practitioners of national and transnational concepts. This view reaffirms the contextualized autonomy of these religious agents, and it leads us to emphasize

\footnotetext{
${ }^{1}$ Department of Humanities, Mount Royal University, Calgary.

Contato: sengler@mtroyal.ca
} 
national aspects of religious glocalization, rather than transnational aspects of religious globalization.

Keywords: Syncretism; Hybridity; Globalization; Glocalization; Tradition; Candomblé; Umbanda.

Não vim para ensinar a reza ao vigário - I do not come carrying coals to Newcastle ${ }^{2}$. Não trato aqui das religiōes afro-brasileiras. Investigo certas implicações teóricas que são implícitas na maneira que essas tradições são usadas como exemplos do syncretism e hibridez pela discipline de Religious Studies na América do Norte e na Europa Ocidental. Mais especificamente, analiso as maneiras em que o candomblé e a umbanda foram apropriados e negligenciados, respectivamente, em discussões das relações entre a 'tradição' africana e a cultura brasileira.

A apropriação das Afro-Brazilian religions pelos estudiosos da religiāo norte-americanos e europeus é problemática por três motivos. Primeiro, o candomblé serve, quase exclusivamente, como o único exemplo das tradições afro-brasileiras na literatura de Religious Studies. Segundo, é analisado com um contraste implícito com a cristianismo - como se fosse o exemplo arquetípico do sincretismo. Isto, argumentarei, reflete e reforça uma relação distorcida entre a religião e uma visão estática da 'tradição'. A ênfase resultante nas origens sobressalta a natureza estática das religiōes de origem (no caso do candomblé, principalmente as tradições iorubás e o catolicismo ibérico) e ela ignora o trabalho contínuo da invenção e da manutenção das tradições religiosas. Terceiro, os aspectos transnacionais do candomblé foram vem sendo acentuados na literatura recente, com o resultado que a especificidade do contexto brasileiro está sendo ignorada. Ambas dessas últimas tendências retiram a ênfase devida à agência religiosa dos praticantes brasileiros. Além

${ }^{2}$ Este artigo utiliza trechos selecionados de outras publicações (Engler, 2005b; 2005a; 2009a; 2009c; and A aparecer-b). O argumento do artigo é original. Utilizo aspas simples e duplas para marcar o uso e a menção respectivamente: p. ex., religião, sem aspas, é o uso direto do termo; religiāo refere ao uso ou à definição dele; e religiāo indica uma citação. 
do mais, elas usam modelos teóricos impróprios e ignoram a literatura das ciência sociais brasileiras ${ }^{3}$. Argumento aqui que a umbanda seria um exemplo mais apropriado. Ele acentua várias dimensões do hibridismo cultural, salientando o contexto específico do Brasil. Sugerirei que há um paralelo entre este as fatos e a trajetória recente de teorias da globalização. A Religious Studies deveria prestar menos atenção ao sincretismo e o transnacionalismo e mais ao hibridismo e a glocalização. Isto é, o caso de umbanda chama atenção ao contexto nacional importantíssimo das religiōes brasileiras.

O candomblé serve como o exemplo paradigmático do sincretismo na Religious Studies (Stewart; Shaw, 1994, p. 13). É apresentado como uma mistura de elementos africanos e cristãos, caracterizada sobretudo pela identificação dos orixás com os santos. Para dar três exemplos recentes, um resumo da história do cristianismo escreve, "Candomblé exemplifica a fusão de elementos africanos e católicos” (Porterfield, 2007, p. 158); um texto das religiōes mundiais escreve, "Candomblé é um sincretização de práticas católicas e africana..." (Matthews, 2008, p. 372); e um artigo em uma enciclopédia da África e das Américas escreve, “[...] umbanda e candomblé brasileiros, vodun, obeah e santeria do caribe, misturam santos católicos com espíritos" (Juang; Morrissette, 2008, p. 16)

Há dois problemas com este uso do candomblé como o caso prototípico de sincretismo. Primeiro, esta visão é pelo menos meio século fora de moda. Esta linha do argumento foi proeminente no estudo acadêmico

\footnotetext{
${ }^{3}$ Como cientista da religião norte-americano, posso testemunhar a dificuldade de adquirir uma boa coleção de livros e revistas acadêmicas brasileiras. As bibliotecas norte-americanas têm poucos recursos na área. $\mathrm{O}$ acesso on-line, por exemplo desta revista, vem ajudando. Tenho conseguido juntar os clássicos e ficar mais ou menos em cima das novidades, devido à minha estadia de dois anos e meio como professor visitante no Programa de Estudos Pós-Graduados em Ciências da Religião da Pontifícia Universidade Católica de São Paulo (2005-2007, com o apoio dos colegas da PUC, da FAPESP e da CAPES) e devido às minhas visitas anuais ao Brasil (com o apoio da família da minha esposa paulista). Porém, muitos "gringos" que vêm estudar a religião no Brasil preferem passar o seu tempo limitado no campo de pesquisa e não nas livrarias e nos sebos. Aqui, também, a Internet ajuda, por ex., pelo site estantevirtual.com.br.

${ }^{4}$ Voltarei à questão da equação implícita de candomblé e umbanda nesta última citação.
} 
do candomblé dos seus começos até os meados do século vinte (Rodrigues 1935; Ramos, 2001; 1979; Herskovits, 1937). Contudo, o trabalho de Pierre Verger, nos anos 1950, e Roger Bastide, nos anos 1960, enfatizou as raízes africanas do candomblé, caracterizando este modelo de sincretismo como, na melhor das hipóteses, superficial (Maceiro, 1954; Bastide, 1960; Capone, 2007). Segundo, esta visão ignora os recentes movimentos de desincretização e re-africanização no Brasil (Luz, 1996; Silva, 1999; Parés, 2004, p. 194 e seg.; Prandi, 2006).

Isto levanta uma pergunta importante: por que esta misrepresentação continua tão proeminente? Embora os especialistas obviamente não seguem esta pista anacronica, o modelo de sincretismo permanece forte nos textos introdutórios e nas conferências não especialistas. A falha de não corrigir esta misrepresentação reflete, em parte, a ignorância de alguns dos estudiosos norte americanos, e menos os europeus, das literaturas brasileira e francês. Em parte, contudo, reflete o fato que o modelo de sincretismo passa sem ser questionado porque ele se ajusta tão bem com duas pressuposições distorcidas da Religious Studies: a ideia que as religiões são antigas, quer dizer 'tradicionais'; e a ideia que elas podem ser caracterizados por um conjunto fundamental de crenças e práticas, a mistura das quais resulta no sincretismo. A clarificação desses dois pontos salientará o impacto do uso do candomblé como o caso prototípico do sincretismo.

\section{RELIGIÃO, TRADIÇÃO, SINCRETISMO}

No estudo da religião, tradição é sinônimo de religião. A suposição implícita é que os fenômenos religiosos têm alguma conexão vaga porém essencial ao passado. Contudo, a equação de religiōes e tradições invoca a mesma lógica defeituosa pela qual a cristianismo foi etiquetada superstitio na Roma antiga ao passo que o Judaísmo foi considerado religio: a última foi antiga, uma tradição. A prevalência desta suposição ajuda a explicar a negligência curiosa do estudo dos Novos Movimentos Religiosos, quanto às decisões de contratação no campo da Religious Studies. Esta conexão entre 
religiāo e tradição enfatiza a busca das origens, e isso distorce o conceito do 'sincretismo'.

Há um interesse oculto na equação implícita de 'religião' e 'tradição'. Russell McCutcheon (1997) argumenta que o estudo acadêmico da religião aceita sem crítica suposições ao definir a religiāo como um fenômeno distinto (assim legitimando um campo acadêmico autônomo com matéria, métodos, e teorias distintos). Um elemento-chave neste jogo é de projetar a essência da religião no passado, acentuando a distinção entre tradição e modernidade, estática e dinâmica, recepção e inovação. Nesta visão, a vida humana autêntica é arraigada em relações tradicionais ao sagrado. Para McCutcheon, esta conexão entre religião e tradição tem dois problemas principais. Primeiro, ela manifesta uma "política vaga e indefensável da nostalgia," no qual o moderno falta algo relativo ao tradicional. Isto ocorre apesar do fato que "a natureza vaga e subjetiva de tais categorias como a de um 'modo autêntico 'tradicional' da existência humana'" resulta na ausência de "critérios específicos para determinar o status desses valores supostamente arcaicos" (Ibid., 33). Segundo, e ironicamente, esta conexão resulta em um prejuízo contra as comunidades cujas tradiçôes idealizadas são estudadas: “[...] a retórica e a ideologia do tradicionalismo efetivamente manufaturam um nativo estereotipado distinto de, e menos do que, o ser humano ocidental racional, individualista e moderno" (Ibid., 177). Esta crítica nos lembra que as questôes de continuidade e agência, como aquelas de autoridade e legitimidade, são inseparáveis e devem ser examinadas com um olho aos contextos sociais e históricos específicos.

É um erro interpretar religiāo e tradição como equivalentes, vendo as duas como se fossem estáticas, passadas inalteradas do passado ao presente. $\mathrm{Na}$ base desta equivalência, esta visão da tradição como $a$ dada essencializa as religióes, sobressaltando um núcleo putativamente estático das crenças e das práticas, e ela ignora a agência, as capacidades de ação dos praticantes religiosos. Ela ignora o valor de ocupar a posição estratégica da tradição em lutas pelo poder. Eric Hobsbawm distinguiu as tradições genuínas das inventadas: 
[...] à medida que há... referência a um passado histórico, a peculiaridade de tradiçōes 'inventadas' é que a continuidade com este passado é basicamente fictícia. Em resumo, são respostas a situações novas que tomam a forma de referências para velhas situaçôes, ou que estabelecem o seu próprio passado pela repetição quase-obrigatória.” (Hobsbawm; Ranger 1983, p. 1)

O Hobsbawm sugeriu que a invenção da tradição (e [re]invenção de tradições extintas) se tornou mais frequente na modernidade, um período em que os velhos caminhos das tradições genuínas foram ameaçados pela transformação social rápida (Ibid., p. 4-8).

A visão do Hobsbawm, contudo, é modernista demais, apresentando as tradições inventadas como imaginárias em contraste com as tradiçôes autênticas. Este contraste entre as tradições verdadeiras e falsas é indefensável por motivos epistemológicos: "[...] como defendemos 'o verdadeiro passado’... e as tradiçóes 'genuínas'... se aceitarmos que todas as representaçóes culturais - inclusive as acadêmicas - são contingentes e embutidas em um determinado contexto social e político?” (Linnekin, 1992; 250). A tradição rapidamente abre-se às questôes da verdade, da autenticidade, da autoridade, da autonomia, e do poder. Em termos pragmáticos, todas as tradições são, até certo ponto, tanto genuínas como inventadas. No mínimo, é importante considerar até que ponto o ato de receber a tradição como a tradição invoca uma série de julgamentos ativos: "cabe aos crentes, ou pelo menos o seus 'líderes de opinião'... julgar se o estado presente da sua tradição seja 'em sintonia' com um conjunto de supostos 'fundamentais' considerados cruciais para a autenticidade do seu sistema.” (Usarski, 2005, p. 371; ênfase original).

Este discernimento dirige os estudiosos da religião a examinar não a autenticidade das afirmações sobre o que é ou não é tradição, mas a relação entre o conceito da tradição e os seus outros. A tradição é geralmente definida em termos relativos, ocupando um pólo extremo de um conjunto de conceitos opostos. Assim como o sagrado tem um significado determinado em contraste ao profano, e a cultura muitas vezes em contraste à natureza, o 
significado de tradição se torna explícito pela oposição. Em geral, a tradição é considerada (a) estática, antiga, conservadora, unitária, local, contínua, passiva, recebida, e repetitiva, em contraste com aquele que é (b) dinâmico, moderno, reformadoro, plural, global, descontínuo, ativo, inventado, e inovador. Qualquer análise do conceito da tradição envolve assim o esclarecimento da tensão relativa entre tais pares de conceitos. Em geral, a estratégia de inventar (um)a tradição é aquela de insistir que certos fenômenos manifestam as características da lista (a), quando de fato funcionam segundo a lógica da lista (b).

O conceito da tradição ganha peso quando essa tensão conceitual se torna normativa: isto é, onde pares de conceitos descritivos (por ex., velho/ novo, estático/dinâmico, e recebido/inovado) são alinhados com outros pares normativos (por ex., bom/mau, direito/incorreto, e aceitável/inaceitável). É precisamente esta superposição de duas polaridades, uma descritiva e a outra normativa, que faz da tradição um rótulo tão largo e eficaz, com grandes poderes de legitimação, devido à sua identificação com uma suposta autoridade anteriormente estabelecida. Assim, a posse ou a apropriação desta posição estratégica tem grande valor tanto para forças conservadoras como reacionárias. Portanto, existem três desafios para os estudiosos: (1) esclarecer as distinções conceituais em jogo quando alguém fala da tradição (recebido/inventado, antigo/moderno, estático/dinâmico, contínuo/descontínuo, etc.); (2) determinar como essas são ligados a certos julgamentos normativos (verdadeiro/falso, autêntico/inautêntico, etc.); e (3) investigar como as conexóes entre estas polaridades descritivos e normativos legitimam e reificam as construções sociais, institucionais e ideológicos.

Não são somente os colonizadores e agentes da dominação cultural que têm a capacidade de inventar as tradições: a (re)invenção da tradição foi e continua sendo uma importante estratégia indígena e local para a resistência ou a rejeição da colonização, da modernização, e da globalização. Deste ponto de vista, a autenticidade da tradição pode ser enquadrada em termos da autonomia, não em termos da verdade histórica. Assim, a medida da autenticidade se torna o próprio alcance da agência. Nessa ótica, a tradição é "ação temporal volitiva," com o seu contrário sendo "não a mudança mas 
a opressão" (Glassie, 1995, p. 409, p. 396). Por exemplo, como é que descreveríamos a re-invenção Melanésia da tradição pelo discurso de kastom: este discurso é inautêntico porque ele conscientemente apropria e inverte o discurso colonial, ou é autêntico porque ele é um produto da agência indígena (Babadzan, 1988)? Negamos esta última alternativa ao insistirmos que as tradições inventadas pós-coloniais são necessariamente opositoras e contra-hegemônicas, e que "[...] o discurso dos dominantes determina as formas e as estruturas do discurso dos dominados" (Keesing 1989, 41). Os estudos da invenção da tradição levam-nos a rejeitar esta visão: o conceito da tradição delimita um espaço de luta dentro de qual a agência de todos os participantes pode ganhar potência. Devemos ter receio especialmente das perspectivas que minimizam a agência das pessoas religiosas que estudamos. Como Marshal Sahlins observou, "[...] as tradições são inventados nos termos específicos das pessoas que os constroem” (1999, p. 409).

Em soma, a proposta que candomblé é o exemplo prototípico de um processo universal de mistura cultural está duplamente enganadora: ela pressupõe a natureza estática das tradiçôes africanas e cristãs; e ela limita a agência religiosa a um momento histórico de mistura, muitas vezes enquadrada como uma resposta forçada à dominação. Uma perspectiva mais crítica destacaria a agência dos candomblecistas na construção das suas próprias tradições. Uma vez que reconhecemos que o conceito da tradição funciona como "[...] uma categoria interpretativa para referir a determinados pensamentos, práticas, e pessoas que se juntaram em volta de determinadas visóes de continuidade e ruptura sociais, históricas, e/ou religiosas" devemos procurar a analisar os contextos específicos dessas conjunturas (Carbine, 2005, p. 146). Tradição, bem como sincretismo, aponta para processos da negociação cultural. Para estudar tais conceitos, é necessário focalizar o contexto local, e não as formas religiosas supostamente universais ou globais.

\section{SINCRETISMO OU HIBRIDISMO?}

A disciplina de Religious Studies contínua caracterizando o Candomblé como o exemplo paradigmático do sincretismo, e isso nos alerta para 
certas pressuposições distorcidas deste campo de estudos. O conceito do sincretismo acentua as raízes supostamente puras da mistura religiosa, assim refletindo e reforçando a equação implícita de religião e tradição. Como tal, ele ignora o trabalho contínuo que é necessário para construir e manter a tradição (seja autêntica ou inventada). O conceito do hibridismo é mais útil para destacar as questões da mistura cultural.

Os estudiosos de Religious Studies continuam falando do sincretismo durante uma geração acadêmica inteira enquanto a maior parte dos seus colegas, em outras áreas das ciências humanas e sociais, falam do hibridismo. Um estudo comparativo do uso de sincretismo e hibridismo em bancos de dados acadêmicos (em 2007) mostra que as publicações de Religious Studies usam sincretismo $95 \%$ do tempo, enquanto as publicações acadêmicas mais gerais usam hibridismo 99\% do tempo (Engler 2009c, p. 3). A hibridismo veio à proeminência principalmente na teoria pós-colonial, onde, já faz mais de uma década, foi "um dos termos mais largamente empregados e discutidos." (Ashcroft et al., 1998, p. 118). O conceito teve uma grande influência em outros campos, cruzando com vários termos relacionados, tanto velhos como novos: por. ex., aculturação, articulação, bricolagem, cosmopolitanismo, creolização, cross-culturalism, etnoconvergência, fusão, heterogeneidade, intermediação, intersticialidade, mélange, mestizaje, mongrelization, multiculturalismo, identidade múltipla, pasticho, poligênese, polifonia, subalternidade, terceiro espaço, transculturação, transnacionalismo, etc. O fato idiossincrásico de Religious Studies não ter seguido este rumo terminológico reflete o fato que sincretismo incorpora pressuposiçóes quanto às questóes das origens e da visão reificada das tradiçóes religiosas como artefatos antigos, contínuos, estáticos, etc.

Há, naturalmente, um debate complexo sobre a origem, a história, as lealdades, e o valor do conceito de sincretismo (Stewart 1999; Leopold; Jensen, 2004; Martin; Leopold, 2004). (Muitos dos pontos positivos e negativos do conceito também se aplicam no caso 'da hibridismo' [Kraidy 2002; Hutnyk, 2005; Engler, 2009c].) A crítica mais óbvia é que “[...] o sincretismo essencializa demais, dando a impressão que houve uma vez certas raças puras e bem-comportadas, antes que os novos vira-latas religio- 
sos furaram a cerca” (Johnson, 2002a, p. 302). Contudo, é possível traçar uma distinção largamente útil entre os dois conceitos: o sincretismo é uma mistura de elementos religiosos; o hibridismo é uma mistura mais ampla de elementos culturais. Isto é menos uma definição rigorosa do que um indicador do valor do hibridismo no estudo dos fenômenos religiosos em um mundo cada vez mais globalizado.

O sincretismo é geralmente visto como um fenômeno interno à religião. Michael Pye o define como "[...] a coexistência ambígua e temporária de elementos de diversos contextos religiosos e não-religiosos dentro de um modelo religioso coerente" (1971, p. 93). Charles Stewart oferece "[...] a definição mais larga e mais geral de sincretismo: a combinação de elementos de duas ou mais tradições religiosas diferentes dentro de uma conjuntura especificada” (2004, p. 282). Nestor Garcia Canclini define o sincretismo como "uma combinação de práticas religiosas tradicionais" (2006b, p. xxviii).

A hibridismo, porém, reconhece mais diretamente as interações complexas entre os fenômenos religiosos e os seus contextos históricos, políticos, sociais e culturais. A distinção não é nítida na prática; ela aponta para dois extremos de um espectro. Os estudiosos da religião destacam elementos religiosos nas suas análises de formas híbridas, mas, em geral, o uso do hibridismo destaca uma variedade mais abrangente de dimensóes culturais da modificação religiosa. Além de concentrar na mistura cultural mais amplamente, o conceito do hibridismo acentua a normalidade, a criatividade, o dinamismo e as implicações políticas deste tipo de mistura. Ulf Hannerz por exemplo, acentua as vantagens do "ponto de vista creolisto":

Ele identifica a própria diversidade como uma fonte da vitalidade cultural; ele exige de nós que vejamos a complexidade e a fluidez como um desafio intelectual e não como algo para ser evitado. Ele deve apontar-nos para modos de ver os sistemas da significação sem ocultar as suas conexôes com os fatos do poder e da vida material. (1987, p. 556)

O conceito do hibridismo, portanto, oferece duas vantagens imediatas para o estudo da religião: ele destaca as relações complexas entre as religiōes e outras dimensões das suas culturas e sociedades (facilitando a critica de 
uma distinção exagerada entre religião e cultura); e ele abre portas para asa discussões disciplinares existentes dessas questões (Engler, 2009c).

James Clifford propõe uma distinção útil entre dois tipos da hibridismo: o hibridismo de raízes e o de caminhos (roots e routes) (Clifford 1997; veja Friedman, 2002). Peter Wade esclarece esses dois conceitos:

O hibridismo de raízes... depende de um sincretismo simples de dois totais anteriores para fazer um terceiro inteiro e novo. Neste modo teleológico, as origens e a pertinência são supremas, e os essencialismos exclusivos podem ser facilmente reproduzidos. O hibridismo de caminhos... depende de movimentos diaspóricos imprevisíveis, cria redes complexas instáveis que não são redutíveis a progressões teleológicas, mas que se-movem para cá e para lá irregularmente no tempo e no espaço. Neste modo, os caminhos e o movimento são supremos e o exclusivismo dá lugar às identidades mais inclusivas baseadas, por exemplo, na percepção de interesses e metas comuns, e não nas origens comuns (Wade, 2005, p. 256-57) ${ }^{5}$.

De um lado, o hibridismo de raízes, interpretado estreitamente, reproduz a visão essencialista do sincretismo, e o hibridismo de caminhos serve "em algum sentido como uma progressão além de ou um desafio a este outro, se não como o seu contrário simples" (Ibid., p. 257). Do outro lado, Wade faz duas colocações que ressuscitam o valor do hibridismo de raízes: "[...] pensar em termos de raízes e origens não é necessariamente tão essencialista e exclusivista como poderia parecer de primeiro [...]"; e "[...] o hibridismo de caminhos não pode escapar o hibridismo de raízes. Os dois são mutuamente implicados e co-dependentes" (Ibid., p. 257). Isto é, além de ser cauteloso no nosso uso desses conceitos, temos de reconhecer que a distinção aponta para algo significante na percepção das insiders das formas culturais hibrídas: temos de levar em conta que os insiders muitas vezes veem e, termos de origens o que pode parecer, do ponto de vista acadêmico, uma

${ }^{5}$ Como os termos visualmente atrativas de Clifford (roots e routes) são homófonos e portanto podem causar confusão em certos contextos, proponho nos meus textos em inglês os termos alternativos: os hibridismos de origem e de encontro. Em português, os termos de Clifford ficam bem assim mesmo. 
invenção de tradição. Como vimos acima, é sempre importante prestar atenção nas inter-relações deste conceitos.

Prudência analítica é importante por três motivos. Primeiro, a distinção entre os hibridismos de raízes e de caminhos não pressupõe que as raízes do primeiro são puras nem que as tradiçóes que se encontram no segundo são híbridas. Segundo, a distinção não é aquilo entre passado e presente, entre tradição e inovação: as origens podem ser desenvolvimentos atuais e os caminhos históricos. Terceiro, tanto os fatos acadêmicos como as invençôes dos insiders são relevantes para ambos. (Assim, a ênfase de Wade na teleologia está confusa: caracteriza o hibridismo de raízes do ponto de vista da perspectiva crítica que ele tenta ultrapassar, e assim perde a oportunidade de pensar este tipo de hibridismo de uma maneira mais sensível.)

Esta distinção entre tipos de hibridismo enquadra perspectivas e questôes distintas, não realidades híbridas distintas, é heurística não ontológica. O hibridismo da origem enquadra (i) as percepçôes insider da origem e caráter de formas culturais distintas, seja ou não de um ponto de vista essencial e exclusivisto, e (ii) a atenção acadêmico (limitada) à história interna das doutrinas, práticas e formas institucionais (inclusive os desenvolvimentos atuais). A escolha do estudioso ou do insider de invocar este tipo da hibridismo destaca uma ênfase geral nas origens, mas deixa em pauta muitas perguntas complexas. Por exemplo e em geral, a perspectiva insider enfatiza que o candomblé é uma religião africana, mas os estudiosos debatem o quanto que esta origem é construída, inventada ou imaginada. Assim, o 'hibridismo de raízes' pode rotular a perspectiva insider sem afirmar que isto seja a realidade completa. Assim também, as perspectivas insider enfatizam que a umbanda (manifestando um espectro de posições), às vezes apontam para raízes na África, às vezes na Índia, no Brasil, na Atlântida, ou em outros planetas, e às vezes reclamam uma universalidade sem raízes geográficas. Neste caso os conceitos de hibridismos de raízes e de caminhos podem distinguir aspectos diferentes de uma maneira heurística.

Ambos estes conceitos de hibridismo podem ajudar na análise dos desenvolvimentos históricos ou contemporâneos, tanto as religiōes diaspóricas quanto as interações mais constrangidas da coexistência de longo 
prazo dentro de um contexto cultural específico. São complementares como instrumentos analíticos. Refletem o presente tanto como o passado, e o contexto tanto como os fenômenos internos da própria mistura. (Por exemplo, o desenvolvimento da umbanda não é uma mistura diaspórica franca; é um desenvolvimento interno a uma sociedade bem estabelecido, embora eminentemente híbrido e pós-colonial: os caminhos neste caso são menos diaspóricos do que urbanas.) Hibridismo de caminhos demarca o contexto social da interação cultural, as estratégias e táticas da influência mútua, e a criatividade dos agentes culturais. Do outro lado, ele necessariamente invoca as suas origens; ele reflete o passado tanto como o presente. $\mathrm{O}$ hibridismo de raízes aponta a construção da novidade (o que não é um movimento teleológica, querendo chegar na mistura). Do outro lado, ele reflete circunstâncias históricas, religiosas, e políticas específicas. As discussões do hibridismo são mais úteis quando elas enfatizam as tensões que estabelecem, priorizam, naturalizam, e sacralizam as divisões sociais.

Proponho aqui um terceiro tipo e hibridismo. À primeira vista, o hibridismo de raízes tem um enfoque diacrônico e internalista, salientando as origens, e o de caminhos tem um enfoque síncrono, salientando o contexto social da interação cultural, as estratégias e táticas da influência mútua, e a agência dos participantes. $\mathrm{O}$ caso da umbanda é híbrido em ambos estes sentidos, mas tem algo mais. Sugiro que o conceito do hibridismo da refração aponta o fato das distinções sociais dentro de uma sociedade serem simbolicamente repetidos, elididos, ou invertidos dentro de um sistema religioso, resultando em um espectro da variação doutrinal, ritual ou institucional (Engler, 2009e). Obviamente, este tipos de hibridismo não são mutuamente exclusivas; servem para destacar aspectos de casos específicos.

A umbanda, por exemplo, apresenta um espectro de grupos que englobam e refletem as mesmas divisões de raça e de classe que enquadraram o seu desenvolvimento no início do século vinte. Ele não é uma religião diaspórica (hibridismo de caminhos). De fato originou-se na mistura de raízes religiosas distintas, primariamente o candomblé e o kardecismo, elas mesmas híbridas. Mas parar por aqui omitiria uma dimensão crucial do seu hibridismo: a maneira em que a umbanda continua manifestando uma série 
da tensões que foram ligadas às suas raízes híbridas e que continuam sendo constitutivas da sociedade brasileira. O conceito do hibridismo da refração refere a uma relação homóloga entre um conjunto de distinções sociais em uma determinada sociedade e a repetição, elisão, ou inversão destas mesmas distinçôes dentro de um sistema de crenças e práticas religiosas daquela sociedade.

A Umbanda é uma religião moderna que engloba, reflete, atravessa, e enfim reforça distinções sociais importantes da sociedade brasileira. É um caso importante do hibridismo da refração porque a sua origem, trajetória, e posição são tão intimamente atadas com questões de raça e classe no Brasil, e porque ela reflete essas tensões na sua elaboração doutrinal, formas rituais, e institucionalização. Vários estudiosos já observaram que a umbanda reflete a sociedade brasileira. Peter Fry argumenta que Umbanda reflete as estruturas sociais e políticas de Brasil (1982). Renato Ortiz nota que "A ideologia umbandista conserva e transforma os elementos culturais afro-brasileiros dentro de uma sociedade moderna...” (1999, p. 212). Maria Helena Villas Boas Concone observa que vários espíritos umbandistas são retirados da realidade nacional (2001, p. 282). Brumana e Martinez descrevem a umbanda como um "culto subalterno" que "elabora simbolicamente as condiçôes sociais do cliente.” (1989, p. 45) Patrícia Birman salienta o compromisso simbólico e ritual da umbanda com as realidades sociais da sua freguesia:

A possessão no candomblé envolve palco e platéia em cenas que são tão mais perfeitas quanto mais acionam critérios irredutíveis ao mundo civilizado - mundo da alteridade que é reconhecido por esse critério e valorizado na africanidade que apresenta. Já a possessão umbandista ... [é] tão mais digna de crédito quanto mais acionar contextualmente a sua relação com o mundo tal como experimentado pelos seus assistentes. O que vale, nesse caso, é o quanto o espírito possuído puder fazer valer naquele palco, as referencias sócias e históricas que são suas e de sua platéia, tornando patente a continuidade que possui com essa. (Birman, 1995, p. 44-45)

O que proponho acrescentar a este reconhecimento - que a umbanda é especialmente responsivo às estruturas e a tensoes da sociedade brasileira - é uma caracterização mais exata desta sensibilidade. Não é uma relação 
entre um tipo uniforme ou genérico da umbanda e a sociedade brasileira em um sentido geral. É uma relação entre variantes distintas de umbanda e tensōes sociais específicas (Engler, 2009b). Quer dizer, a umbanda manifesta a hibridismo da refração. (Poderíamos afirmar o mesmo de muitas outras tradições religiosas, p. ex., os pentecostalismos globais e o espectro de tradições influenciadas pelo espiritismo kardecista em várias partes de América Latina.)

Duas afirmações importantes seguem desta comparação do sincretismo e do hibridismo. A preferência idiossincrásica de Religious Studies para o conceito do sincretismo salienta a sua ênfase no hibridismo de raízes à exclusão do hibridismo de caminhos: super-enfatiza a questão das origens autenticamente tradicionais e assim sob-enfatiza os processos contínuos da mistura cultural. Segundo, esta distorçao, que se manifesta na apropriação do candomblé como o ícone do sincretismo, sugere que seria mais apropriado enfatizar a umbanda como um exemplo de tipos distintos de hibridismo. O exemplo da umbanda desta o hibridismo, e não o sincretismo, e isso provocaria os estudiosos dos fenômenos religiosos a prestarem mais atenção no contextos sociais das misturas religiosas e culturais.

\section{O CANDOMBLÉ E O TRANSNACIONALISMO}

A visão estreita demais da Religious Studies sobre o sincretismo distorce o seu retrato tanto do candomblé como de umbanda. Esta seção deste artigo investiga uma outra fonte de distorções, uma ênfase recente na natureza transnacional do candomblé. Efetivamente, esta maneira de enquadrar o candomblé sobre-enfatiza o hibridismo de caminhos, com o resultado que retira atenção da agência participantes religiosos no seu contexto específico.

Em um livro importante, J. Lorand Matory defende a natureza transnacional de Candomblé:

[...] a economia política, o vocabulário iconográfico, e os discursos interpretativos produzidos pelo candomblé, e os que o produziram, nunca foram somente brasileiros, somente africanos, e nem somente brasileiros e 
africanos. Eles sempre foram radicalmente transnacionais e, em particular, circum-Atlânticos, mesmo no meio do século dezenove. (Matory, 2005, p. 17 ; 1999)

A ênfase do Matory no diálogo transnacional é um corretivo importante e necessário, destacando o fato que os grupos iorubá, na África e nas Américas, influíram-se e continuam fazendo assim. Como tal, o estudo do Matory é contribuição significativa para a literatura acadêmica sobre a diáspora africana dentro do paradigma da 'história Atlântica' (Gilroy, 1993; Mann; Bay, 2001; Manning, 2003). O argumento dele de fato insiste que as tradições iorubá são, no sentido crítico, tradições, tão dinâmicas, dialógicas e flexíveis como outras (inclusive, naturalmente, o catolicismo, o kardecismo e o pentecostalismo): são igualmente capazes de insistir na continuidade pura com o passado (verdadeiro e/ou imaginado); e, no contexto do colonialismo, foram mais suscetíveis à imaginação dos outros quanto a sua posição tradicional. Isto é, Matory desafia a pressuposições de que as tradições africanas diaspóricas se desenvolveram independentemente de raízes africanas locais, estáticas, conservadoras e puras.

Contudo, o fato do Matory concentrar unicamente no candomblé é potencialmente problemático, à medida que ele tira conclusões quanto “à experiência afro-americana” em todas as partes das Américas (Matory 2005, p. 292). Ele vai alem de posições acadêmicas que o veem o candomblé como se fosse um eco secundário derivado da África ou uma resposta forçada a uma sociedade colonial escravo. Ele reafirma "o papel da agência afro-americana (inclusive a afro-brasileira) na criação dessas formas de representação cultural e de auto-representação" (Ibid., p. 16). Porém, o candomblé é de certo modo única entre as tradições afro-brasileiras na sua relação dinâmica e mútua entre as visões dos insiders e os outsiders (especialmente os antropólogos e os intelectuais da cultura popular) e também quanto ao grau de atenção que já recebeu de estudiosos nacionais e estrangeiros. O Matory crítica a historiografia 'anti-essencialista' que vê a ênfase nas raízes puras iorubá como uma “invenção da África” na parte dos estudiosos: segundo ele, esta visão atribui a agência aos estudiosos brancos, negando-a aos afro-brasileiros (Matory, 
2005, p. 45; Dantas, 1982; Motta, 1996; Teixeira, 2006; Despland, 2008). Mas, de fato, esta é uma dicotomia falsa. A agência de candomblecistas inclui a apropriação criativa e autônoma da idéia da pureza nagô (iorubá), como proposta por Edson Carneiro, Ruth Landes, Roger Bastide e outros (Carneiro, 1977; Landes, 1947; Bastide, 2000). O diálogo contínuo com a África não deve ser visto como a característica principal que faz do candomblé uma religião afro-atlântica. É um de vários fatores que os afro-brasileiros utilizam estrategicamente no trabalho de realizarem a suas identidades e inter-relações dentro do contexto brasileiro. O Matory está certo em notar que o candomblé tem uma dimensão transnacional, mas esta não é tão central quanto ele insiste, e nem esta deve ser generalizada sem estudos empíricos às outras tradições afro-brasileiras, e muito menos à umbanda.

À medida que iorubá sinaliza uma ponte transnacional entre a África e o Brasil, a fundação desta ponte é instável tanto historicamente como socialmente e isto é o caso nos dois lados do Atlântico. Isto não quer dizer que a denotação de 'nagô' mudou-se ao ponto que as conexões históricas com as crenças e práticas africanas foram partidas; obviamente, isto é não o caso (Matory, 2005; Luz, 1996; Parés, 2007; Sweet, 2003). (Até 20 milhôes de Brasileiros auto-identificam com a linhagem iorubá [Abímbólá 2004, 318].) As apelações à pureza de origens iorubá desempenham um papel ideológico estratégico, por exemplo nos processos de e debates sobre a re-africanização, de-sincretização, de-catolicização, etc. O Matory destaca os dois lados destes processos:

A africanidade também é constituído por uma genealogia de afirmações e práticas interessadas, que podem ser invocadas seletivamente como precedentes. A naturalização dessas afirmaçôes e práticas depende do contexto e não é permanente. Em outras palavras, as práticas explícitas e formais e a lógica subjacente das culturas africanas e afro-americanas... podem passar por modificações enormes sem o resultado que estas culturas se tornam objetivamente não africanas. (2005, p. 15)

A 'africanidade' aqui é definido quanto ao uso estratégico do discurso e ainda procura manter um sentido 'objetivo' do 'africano'; isto é, o conceito 
é tanto verdadeiro objetivamente como construído discursivamente. Não há nenhum problema com esta visão, enquanto que o meio termo é preservado. Seria indefensável reconhecer a agência dos afro-brasileiros nas suas apelações à África no seu trabalho de construir as suas identidades religiosas e culturais, e ao mesmo tempo considerar que os termos como 'iorubá' têm referentes transnacionais estáveis, sejam arraigados na África ou não.

Esta ambiguidade destaca o contexto local, embora com os fatores transnacionais sempre em visto. Como Joseph M. Murphy observa, "é difícil argumentar que o modelo de diáspora bate com o estado contemporâneo das tradições religiosas iorubá” (Murphy 2010, p. 407). De um lado, ao definir iorubá, a questão de origens tende a acentuar o contexto histórico africano, por exemplo nas discussões recentes das tradições neo-iorubá. Porém, isto problematiza o conceito de iorubá, sendo que, como o Matory aponta, tradições iorubá africanas e americanas (em termos gerais) se desenvolveram em parte pelo diálogo. Definir o 'iorubá' como puramente africano e histórico ignora o dinamismo transnacional deste grupo de tradições. Assim, ele pressupõe uma ênfase na pureza de raízes africanas. Porém, esta ênfase precisa ser examinada e não pressuposta, especialmente dada a sua prevalência nas próprias tradições que se identificam com essas raízes (Matory, 2005, p. 115-148; Selka, 2007, p. 13). Como Robin Law observa, com referência ao Matory, "[...] as etnicidades africanas foram transformadas pelo processo da deslocação pelo Atlântico. E, de modo inverso,... as novas identidades étnicas construídas na diáspora poderiam retornar para a terra de origem pelo repatriamento dos ex-escravos à África” (Law, 1997, p. 205; Parés, 2007, p. 25; Matory, 2005). Do outro lado, uma ênfase no encontro e diálogo diaspóricos é problemático porque vê qualquer modificação como sendo suplementar à essência da cultura iorubá. Por exemplo, quando Law fala de "novas identidades étnicas" isto burla a questão de se essas identidades são ou não iorubá. Não devemos correr para essencializar a África pelo encontro dos seus ecos nas Américas, nem usar a geografia e a cronologia para separar radicalmente as 'antigas' tradições africanas das 'novas' americanas. Há verdade nos dois lados, e é necessário uma consideração cuidadosa de casos específicos para averiguar os detalhes. 
Há uma lição clara aqui com respeito ao estudo da umbanda. Se caracterizarmos as tradições afro-brasileiros de qualquer desses modos - seja como construções românticas ou como descendentes (ou representações) autênticas de crenças e práticas africanas - obscurecemos e marginalizamos as características principais da umbanda. Isto é, a ênfase tanto na invenção como na pureza das origens africanas faz da África a questão principal, e assim deixar de lado o contexto social e político refrangido pelo espectro das formas doutrinais e rituais da umbanda. Focaliza um mito de origem e não as funções daquele mito. Focaliza o sincretismo primordial e não as estratégias da formação de identidade que constroem e mantém a tradição. Como nota o Selka (2007, p. 7),

O Candomblé é possivelmente a mais bem conhecida das religiōes derivadas da África e praticadas no Brasil. A sua popularidade em parte origina-se da crença comum que o candomblé é mais perto às suas origens africanas do que as suas alternativas, como a umbanda, que integraram mais completamente as crenças e práticas cristãs, entre outras européias.

Esta citação sublinha como o candomblé - visto a religião afro-brasileira paradigmática e o exemplo chave do sincretismo - serve como a medida de umbanda, relegando-a a um nível secundário, em virtude da sua maior distância da África e do momento original de mistura. Ao mesmo tempo, Selka poderia ir além disso se destacasse o valor de não aceitar esta caracterização. Enquadrar a umbanda como uma 'alternativa' entre "[...] as religiōes derivadas da África [...]” ignora a sua relação com o kardecism e as suas distancia doutrinal e ritual das tradições afro-brasileiras. O Selka não é o único, nem de longe, a caracterizar a umbanda como somente mais uma religião afro-brasileira ${ }^{6}$. A maior parte dos estudiosos de Religious Studies,

\footnotetext{
${ }^{6}$ Obviamente, muitos estudiosos têm uma avaliação mais matizada das complexidades da paisagem religiosa brasileira. Peter Burke, por exemplo, nota que "[...] não se pode dizer que o candomblé é 'puro' enquanto a umbanda... é o híbrido. Está seguro dizer que as tradiçôes africanas são mais importantes no candomblé do que na Umbanda, mas ambas as formas foram hibridizadas ou traduzidas" (2009, p. 103).
} 
se é que conhecem, categorizam a umbanda como um equivalente próximo ao candomblé: "a macumba, o candomblé, e a umbanda" são "Religiōes Derivadas da África” (Jones; Trost 2005, p. 171).

Mesmo a categorização da umbanda como uma religião afro-brasileira omite detalhes importantes: é "[...] uma tradição afro-brasileira nacionalizada” (Johnson, 2002b, 95; p. 45, p. 52-53); é uma de uma variedade das "atividades afro-brasileiras" (Cohen, 2007, p. 30, 214n5). Esta tendência ignora a variação entre os grupos umbandistas. A relação entre a umbanda a o kardecismo complica a sua relação com a África. Isto, em parte, resulta em um complexo espectro de formas doutrinais e rituais, entre terreiros mais parecidos com os do candomblé e centros que têm mais a ver com aqueles do kardecismo. Existem várias diferenças entre o candomblé e a umbanda (Silva 2005, p. 126-127): por exemplo, a umbanda tem um conjunto maior e mais elaborado, em termos de doutrina, de entidades sobrenaturais; ela dá mais ênfase à mediunidade como fonte de serviço a clientes; ela enfatiza menos a divinação; ela enfatiza menos o papel do pai-de-santo no ritual; ela coloca menos ou nenhuma ênfase na iniciação, e mais na autoridade carismática da mediunidade; ela dá mais espaço para a magia (embora menos do que a quimbanda); os seus textos e hinos usam menos o vocabulário africano; e os seus rituais dão mais espaço para elementos cristãos (por exemplo, "O Pai nosso"). Existem exceções, mas exatamente este fato sublinha o espectro de variações internas na umbanda. Reconhecendo estas diferenças, a Véronique Boyer (1996, p. 18) sugere que o candomblé e a umbanda são pólos opostos e irreconciliáveis.

Esses pontos ajudam a explicar a falta relativa de ênfase na umbanda de elementos afro-brasileiros, mas com três qualificações. Primeiro, o ponto básico é que a umbanda é responsivo ao seu contexto social. Segundo, devemos lembrar que estas e outras estratégias não são universais entre todos os grupos umbandistas. Esses desenvolvimentos não caracterizam nenhuma essência da umbanda. Eles apontam para um de muitos eixos ao longo de quais esta tradição religiosa expressa a sua variação interna (Rohde, 2009, 
p. 91). Nem a afirmação e nem a rejeição de raízes africanas é característica de Umbanda (ou melhor, ambos são, dependendo do contexto) ${ }^{7}$.

Terceiro, é essencial reconhecer a centralidade das ideias e atitudes brasileiras quanto à raça (Ibid., p. 85). Três processos no desenvolvimento da umbanda foi estreitamente ligado a questóes de raça e de classe.: (i) o empretecimento do kardecismo, quando os espíritas buscaram rituais mais estimulantes; (ii) o embranquecimento do candomblé, devido ao número crescente de membros brancos, muitas vezes novos imigrantes, e à formação do 'espiritismo baixo' entre as camadas populares; e (iii) a recepção dos espíritos indígenas por certos kardecistas, e a rejeição subsequente desses caboclos como espíritos não desenvolvidos (Carneiro, 1940, p. 276; Camargo, 1961, p. 34-35; Ortiz, 1999, p. 4-45; D. Brown, 1985, p. 11; 1994, 38-48; Hale, 2009, p. 126). Nas décadas seguintes, os grupos institucionalizados distanciaram-se de elementos africanos por processos da legitimação, refletindo em parte o "mito de três raças" e a ideologia da "democracia racial" (DaMatta, 1987, p. 58-85; Fernandes, 2007, p. 38-48, p. 59-63; Guimarães 2003; Magnoli, 2009, p. 143-62). Na rejeição posterior desta ideologia como racista, o posicionamento da umbanda deixou ela com a possibilidade de responder diferencialmente, com um espectro de variantes, do branca ao afro. Refletindo essas questôes, vários umbandistas acentuam fontes distintas da sua própria tradição, raízes africanas, kardecistas, 'brasileiras,' indígenas, védicas, egípcias, esotéricas, Lemurianas e/ou extraterrestres, idéias elaboradas principalmente nas décadas de 1940 e 1950 (Bastide, 1960, p. 445-447; Oliveira, 2008, p. 114-119; Sá Junior, 2004, p. 77-80; Varella, n.d., p. 14-16; Hale, 2009, p. 62-66).

O Candomblé, de outro lado, foi um central de contestação quando o racismo recebeu um olhar mais crítico nas décadas de 1960 e 1970 (Agier, 1992, p. 63, p. 76; Magnoli, 2009, p. 157-162). A Umbanda-em virtude

\footnotetext{
${ }^{7}$ Brígida Malandrino (2010) oferece um argumento rico e inovador, concluindo que a umbanda é bantú, em contraste com o candomblé que tem laços mais fortes com a tradição ioruba (entre outras). Contudo, o seu foco continua nas origens. O meu enfoque é outro: meu trabalho de campo entre umbandistas brancas no interior do estado de São Paulo salienta a relação atual entre a umbanda e o contexto social brasileiro.
} 
da maneira em que ela refrange o seu contexto social em um espectro de formas religiosas - não é tão polarizada quanto o candomblé em face das tensões sociais racializadas.

Resumindo, a Religious Studies não presta atenção suficiente à agência de agentes religiosos em contextos específicos, e um grande motivo para isso é fato da disciplina ver o candomblé como o emblema do sincretismo (uma visão estreita do hibridismo de raízes) e como um fenômeno primariamente transnacional (uma visão globalizada do hibridismo de caminhos). Ambas as visões estão correlacionadas com uma falta de reconhecimento da grande variação interna na umbanda. Na última seção deste artigo, discuto as implicações desses pontos na ótica das teorias recentes da globalização.

\section{A UMBANDA E A GLOBALIZAÇÃO}

Renato Ortiz escreve que a umbanda é a "religião nacional do Brasil" (Ortiz, 1999, p. 96). Na base desta afirmação, seria útil fazer a seguinte pergunta: que diferença faria se a Religious Studies - em vez de propor a candomblé como o arquétipo do sincretismo - tomasse a umbanda como um exemplo-chave do hibridismo cultural? Surgem três vantagens imediatas. Primeiro, sairia do fetichismo de origens que acompanha o sincretismo, e, assim, ofereceria uma visão mais ampla do hibridismo de raízes. Segundo, colocaria mais ênfase na agência dos praticantes religiosos nos processos de construir e mantiver as suas tradições, e, assim, ofereceria uma visão mais matizada da hibridismo de caminhos. Terceiro, e enfatizaria as maneiras em que as tradições religiosas refletem e contribuem para os seus contextos sociais e culturais nacionais, e, assim, salientaria o hibridismo da refração. Concluirei sugerindo que esta trajetória - afastando visões de certa maneira úteis, mas enfim limitadas, do sincretismo e do transnacionalismo em direção à análise de tipos e contextos diferentes do hibridismo - segue aquela das teorias recentes da globalização. Deste ponto de visto, o meu argumento é que a Religious Studies deveria se repaginar teoricamente - to get with the times. 
As teorias da globalização estão entrando uma nova fase: a terceira onda propõe modelos mais complexos e polivalentes, que vão além da ênfase anterior nos processos globais imperialistas, homogeneizantes e hegemônicos, e além do otimismo quanto ao potencial dos processos locais para a criação e a resistência. Historicamente, as teorias de Globalização apareceram ao lado de reações contra três aspectos da teoria de modernização: (i) a sua visão do Oeste (isto é, o eixo norte-Atlântico) como o padrão prescritivo da modernização; (ii) a pressuposição que esta forma da modernidade é única; e (iii) a insistência que o progresso nesta direção era inevitável, ou pelo menos unicamente desejável. A rejeição dessas idéias foi ligada com uma ênfase na resistência local à globalização hegemônica, notavelmente usando os conceitos de 'glocalização' e 'hibridismo' (Canclini, 2006a; Featherstone, 1995; Robertson, 1992; 1995). A 'glocalização' refere-se à interação entre fatores globais e locais, resultando em processos únicos em contextos geográficos e culturais específicos. Refletindo uma ênfase nas modernidades 'múltiplas' e 'entrelaçadas' (Domingues, 2009; Eisenstadt, 2000; Therborn, 2003), os trabalhos recentes analisam a globalização como "um fenômeno pluralista com complexidades multifárias e, em muitos casos, idiossincrasias indeterminadas" (G.W. Brown, 2008, p. 44). Desta perspectiva, o caso da umbanda sublinha as dimensões sociais locais (nacionais e regionais) da apropriação de conceitos e modelos que circulam nos mercados simbólicos transnacionais.

Há três ênfases principais nas teoria da globalização: padronização (McDonaldization); conflito ('choque de civilizações); e glocalização e hibridismo (passagens culturais e mélange global) (Ritzer, 2011; Barber, 1996; Huntington, 1996; Nederveen Pieterse, 2003; Robertson, 2001). O argumento para este último é que o alcance e o passo crescentes dos fluxos globais das pessoas, da informação, e das mercadorias corroem fronteiras de vários tipos, especialmente aquelas do estado-nação. As novas formas híbridas servem como os sinais-chaves da mobilidade, da migração, e do multiculturalismo aumentados, uma índice das relações mais complexas entre as fronteiras culturais e as identidades pessoais e sociais. Este enfoque na glocalização e no hibridismo leva-nos a descartar a ideia que a identidade é fixada e estável, e a explorar a sua articulação contingente e fluída, 
arraigada em vários discursos de idade, classe, gênero, raça, e de posições religiosas, étnicas e nacionais.

O caso da umbanda destaca bem estas questões. Um índice da variação interna da umbanda é a variedade das suas apropriações de conceitos e modelos nacionais e transnacionais. Mais visivelmente, esses servem como matérias-primas na construção de mitos da origem: a umbanda é indígena, egípcia, africana, kardecista, védica, esotérica, lemuriana e, sobre tudo, brasileira. Vemos aqui não uma resistência a, e nem dominação por, correntes transnacionais, mas a sua apropriação estratégica. Além disso, essas estratégias não são uniformes: refletem posições diferentes no espectro doutrinal, ritual e institucional que constitui a variedade das umbandas. À medida que a umbanda manifesta o hibridismo da refração, essas posições refrangem, até certo ponto, posiçôes distintas dentro da sociedade brasileira. Isto afirma a autonomia contextualizada desses agentes religiosos e a necessidade de considerar a especificidade nacional ao estudar a tensão constitutiva deste tipo de glocalização. A umbanda não é uma religião afro-brasileira; é uma tradição híbrida brasileira.

Para resumir, a Religious Studies deve concentrar-se no hibridismo em vez do sincretismo, na umbanda em vez do candomblé. Para fazer isso, deveria aprender as liçôes das teorias da globalização e do hibridismo. $\mathrm{O}$ sincretismo e o transnacionalismo são conceitos valiosos, destacando a natureza híbrida das tradições religiosas e a sua sensibilidade aos processos globalizadores, e reconhecendo o fato que estes processos jogam um papel chave na formação de novas tradições religiosas ao redor do mundo. Porém, uma visão deste tipo da globalização não consegue prestar devida atenção nas forças e agentes locais. As teorias de globalização atuais dão maior ênfase aos contextos locais de recepção. A Religious Studies, como frequentemente, está atrasada. Os estudiosos no campo devem deixar de lado a ideia de que a religião pode ser analisada em termos de processos globais ou universais que podem ser entendidos ou representados com exemplos prototípicos, por exemplo, o candomblé como exemplo do sincretismo e/ou o transnacionalismo. É mais útil estudar a interpenetração dos processos globais e locais, por exemplo, a glocalização e a creolização. Deste ponto de vista, a 
umbanda é um exemplo extremamente valioso, e muito negligenciado, para o estudo dos fenômenos religiosos. Ela manifesta os hibridismos de raízes, de caminhos e, sobre tudo, da refração. A umbanda destaca a interação de fatores transnacionais e locais e salienta a agência religiosa dos seus membros na construção e manutenção das suas tradições.

\section{REFERÊNCIAS}

ABÍMBÓLÁ, Kólá. Yorùbá Diaspora. In: Encyclopedia of Diasporas: Immigrant and Refugee Cultures around the World Melvin Ember, Carol R. Ember e Ian A. Skoggard (Orgs.). New York: Springer, p. 317-26. 2004. AGIER, Michel. Ethnopolitique: racisme, statuts et mouvement noir à Bahia. Cahiers d'Études Africaines 32/125: p. 53-81. 1992.

ASHCROFT, Bill; GRIFFITHS, Gareth; TIFFIN, Helen. Key Concepts in Post-Colonial Studies. New York: Routledge. 1998.

BABADZAN, Alain. Kastom and Nation-Building in the South Pacific. In: Ethnicities and Nations: Processes of Interethnic Relations in Latin America, Southeast Asia, and the Pacific. GUIDIERI, Remo; PELLIZZI, Francesco; TAMBIAH, Stanley J.; HAUER, Rose Wax; ROSENSTEIN, Harris (Orgs.). Austin: University of Texas Press, p. 199-228. 1988.

BARBER, Benjamin R. Jihad vs. McWorld: How Globalism and Tribalism Are Reshaping the World. New York: Ballantine Books. 1996.

BASTIDE, Roger. Les religions africaines au Brésil: Vers une sociologie des interpretations des civilisations. Paris: PUF. 1960.

. Le Candomblé de Babia (Rite Nagô). Paris: Plon. 1958.

BIRMAN, Patrícia. Fazer estilo criando gêneros: possessão e diferenças de gênero em terreiros de umbanda e candomblé no Rio de Janeiro. Rio de Janeiro: Ed. UERJ/Relume Dumará. 1995. 
BOYER, Véronique. Le don et l'initiation. De l'impact de la littérature sur les cultes de possession au Brésil. L'Homme 36/138: p. 7-24. 1996.

BROWN, Diana. Uma história da umbanda no Rio. In: Umbanda e Política. Rio de Janeiro: Marco Zero. 1985.

- Umbanda: Religion and Politics in Urban Brazil. New York: Columbia University Press. 1986.

BROWN, Garrett Wallace. Globalization is What We Make of It: Contemporary Globalization Theory and the Future Construction of Global Interconnection. Political Studies Review 6: 42-53. 2008.

BRUMANA, Fernando Giobellina; MARTINEZ, Elda Gonzales. Spirits from the Margins: Umbanda in São Paulo. Uppsala: Uppsala University Press. 1989.

BURKE, Peter. Cultural Hybridity. London: Polity. 2009.

CAMARGO, Cândido Procópio Ferreira de. Kardecismo e Umbanda: uma interpretação sociológica. São Paulo: Pioneira. 1961.

CANCLINI, Nestor Garcia. Culturas Hibridas: Estratégias para Entrar e Sair da Modernidade. Tradução de Gênese Andrade. São Paulo: EdUSP. 2001. . Introdução. In: Culturas Hibridas: Estratégias para Entrar e Sair da Modernidade. São Paulo: EdUSP, xvii-xliii. 2006b.

CAPONE, Stefania. Transatlantic Dialogue: Roger Bastide and the African American Religions. Journal of Religion in Africa 37/3: 336-70. 2007.

CARBINE, Jason. Shwegyin Sasana: Continuity, Rupture, and Traditionalism in a Buddhist Tradition. In: Historicizing "Tradition" in the Study of Religion. ENGLER, Steven; GRIEVE, Gregory Price (Orgs.). Berlin e New York: Walter DeGruyter, 145-74. 2005.

CARNEIRO, Edson. The Structure of African Cults in Bahia. The Journal of American Folklore 53/210: 271-78. 1940. 
. Candomblés da Bahia. 5 ed. Rio de Janeiro: Civilização Brasileira. 1948.

CLIFFORD, James. Routes: Travel and Translation in the Late Twentieth Century. Cambridge, MA: Harvard University Press. 1997.

COHEN, Emma. The Mind Possessed: The Cognition of Spirit Possession in an Afro-Brazilian Religious Tradition. Oxford: Oxford University Press. 2007.

CONCONE, Maria Helena Villas Boas. Caboclos e pretos-velhos da umbanda. In: Encantaria brasileira: o livro dos mestres, caboclos e encantados, Reginaldo Prandi (Org.). Rio de Janeiro: Pallas, p. 281-303. 2001.

DAMATTA, Roberto A. Relativizando: Uma introdução à antropologia social. Rio de Janeiro: Rocco. 1987.

DANTAS, Beatriz Góis. Repensando a pureza nagô. Religiāo e Sociedade 8: 15-20. 1982.

DESPLAND, Michel. Bastide on Religion: The Invention of Candomblé. London: Equinox. 2008.

DOMINGUES, José Maurício. Modernity and Modernizing Moves: Latin America in Comparative Perspective. Theory, Culture \& Society 26/7-8: 208-27. 2009.

EISENSTADT, S.N. Multiple Modernities. Daedalus 129/1: p. 1-29. 2000.

ENGLER, Steven. Constructionism vs. What? Religion 34/4: 291-313. 2004.

. Tradition. In: The Brill Dictionary of Religion, Kocku von Stuckrad (Org.). Leiden: Brill, 1907-11. 2005a.

. Tradition's Legacy. In: Historicizing "Tradition” in the Study of Religion, Steven Engler e Gregory P. Grieve (Orgs.). Berlin e New York: Walter DeGruyter, p. 357-78. 2005 b. 
. Two Problems with Constructionism in the Study of Religion. Revista de Estudos da Religião (Rever) 5: 28-34. 2005c.

. Review of James R. Lewis e Olav Hammer, orgs. The Invention of Sacred Tradition." Religion 39/4: p. 395-96. 2009a.

. Ritual Theory and Attitudes to Agency in Brazilian Spirit Possession. Method and Theory in the Study of Religion 21/4: p. 460-92. $2009 \mathrm{~b}$.

. Umbanda and Hybridity. Numen [Leiden] 56/5: 545-77. 2009c.

. A aparecer-a. Hybridity. In: Vocabulary for the Study of Religion, Kocku von Stuckrad e Robert A. Segal (Orgs.). Leiden: Brill.

. A aparecer-b. Umbanda and Africa. Nova Religio: The Journal of Alternative and Emergent Religions 15/4.

FEATHERSTONE, Mike. Undoing Culture: Globalization, Postmodernism, and Identity. London: Sage. 1995.

FERNANDES, Florestan. 2007 [1972]. O negro no mundo dos brancos. 2a ed. São Paulo: Global Editora.

FRIEDMAN, Jonathan. From Roots to Routes: Tropes for Trippers. Anthropological Theory 2/1: 21-36. 2002.

FRY, Peter. Para inglês ver: identidade e política na cultura brasileira. Rio de Janeiro: Zahar. 1982.

GILROY, Paul. The Black Atlantic: Modernity and Double Consciousness. Cambridge, MA: Harvard University Press. 1993.

GLASSIE, Henry. Tradition. Journal of American Folklore 108: 395-412. 1995.

GUIMARÃES, Antonio Sérgio Alfredo. Democracia racial. (2003), http:// tinyurl.com/y99cbwx.

HALE, Lindsay L. Hearing the Mermaid's Song: The Umbanda Religion in Rio de Janeiro. Albuquerque: University of New Mexico. 2009. 
HANNERZ, Ulf. The World in Creolisation. Africa: Journal of the International African Institute 57/4: 546-59. 1987.

HERSKOVITS, Melville J. African Gods and Catholic Saints in New World Negro Belief. American Anthropologist (n.s.) 39/4-1: 635-43. 1937.

HOBSBAWM, Eric; RANGER, Terence. (Orgs.). The Invention of Tradition. Cambridge: Cambridge University Press. 1983.

HUNTINGTON, Samuel P. The Clash of Civilizations and the Remaking of World Order. London: Simon and Schuster. 1996.

HUTNYK, John. Hybridity. Ethnic and Racial Studies 28/1: 79-102. 2005.

JOHNSON, Paul Christopher. Migrating Bodies, Circulating Signs: Brazilian Candomble, the Garifuna of the Caribbean, and the Category of Indigenous Religions. History of Religions 41/4: 301-27. 2002a.

. Secrets, Gossip, and Gods: The Transformation of Brazilian Candomblé. Oxford e New York: Oxford University Press. 2002b.

JONES, Carolyn M.; TROST, Theodore Louis. Teaching African American Religions. New York: Oxford University Press. 2005.

JUANG, Richard M.; MORRISSETTE, Noelle Anne. Culture and Religion. In: Africa and the Americas: Culture, Politics, and History: A Multidisciplinary Encyclopedia, Richard M. Juang e Noelle Anne Morrissette (Orgs.). New York: ABC-CLIO, 1, 11-18. 2008.

KEESING, Roger M. Creating the Past: Custom and Identity in the Contemporary Pacific. Contemporary Pacific 1/1-2: 19-42. 1989.

KRAIDY, Marwan M. Hybridity in Cultural Globalization. Communication Theory 12/3: 316-39. 2002.

LANDES, Ruth. The City of Women. New York: MacMillan. 1947.

LAW, Robin. Ethnicity and the Slave Trade: 'Lucumi' and 'Nago' as Ethnonyms in West Africa. History in Africa 24: p. 205-19. 1997. 
Leopold, Anita M.; Jeppe Sinding Jensen, Orgs. Syncretism in Religion: A Reader. London: Equinox. 2004.

LINNEKIN, Jocelyn. On the Theory and Politics of Cultural Construction in the Pacific. Oceania 62: 249-63. 1992.

LUZ, Marco Aurélio. A tradição dos orixás, continuade transatlântica. In: Sincretismo religioso: o ritual afro. Anais do IV congresso afro-brasileiro. LIMA, Tânia (Org.). Recife: Fundação Joaquim Nabuco/Editora Massangana, 155-62. 1996.

MAGNOLI, Demétrio. Uma gota de sangue: história do pensamento racial. São Paulo: Editora Contexto. 2009.

MALANDRINO, Brígida Carla. 'Há sempre confiança de se estar ligado a alguém': dimensões utópicas das expressões da religiosidade bantú no brasil. Tese de doutorado em Ciências da Religião, Pontifícia Universidade Católica de São Paulo (PUC-SP). 2010

MANN, Kristin; BAY, Edna G. (Orgs.). Rethinking the African Diaspora: The Making of a Black Atlantic World in the Bight of Benin and Brazil. London e Portland, OR: Frank Cass. 2001.

MANNING, Patrick. Africa and the African Diaspora: New Directions of Study. Journal of African History 44: p. 487-506. 2003.

MARTIN, Luther H.; LEOPOLD, Anita M. New Approaches to the Study of Syncretism. In: New Approaches to the Study of Religion. Volume 2: Textual, Comparative, Sociological and Cognitive Approaches. GEERTZ, Peter Antes, Armin W.; WARNE, Randi R. (Orgs.). Berlin: De Gruyter, 93-107. 2004. MATORY, J. Lorand. Jeje: repensando naçôes e transnacionalismo. Mana - Estudos de Antropologia Social 5/1: p. 57-80. 1999.

. Black Atlantic Religion: Tradition, Transnationalism, and Matriarchy in the Afro-Brazilian Candomblé. Princeton: Princeton University Press. 2005. 
MATTHEWS, Warren. World Religions. 6th ed. Belmont, CA: Cengage Learning. 2008.

MCCUTCHEON, Russell T. Manufacturing Religion: The Discourse of Sui Generis Religion and the Politics of Nostalgia. Oxford: Oxford University Press, 1997.

MOTTA, Roberto. A invenção da África: Roger Bastide, Edison Carneiro e os conceitos de memória coletiva e pureza nagô. In: Sincretismo religioso: o ritual afro. Anais do IV congresso afro-brasileiro, LIMA, Tânia (Org.). Recife: Fundação Joaquim Nabuco/Editora Massangana, p. 24-32. 1996. MURPHY, Joseph M. Yoruba Religions in Diaspora. Religion Compass 4/7: 400-409, 2010.

Nederveen Pieterse, Jan. Globalization and Culture. Lanham, MD: Rowman \& Littlefield Publishers. 2003.

OLIVEIRA, José Henrique Motta de. Das macumbas à umbanda: uma análise histórica da construção de uma religião brasileira. Limeira: Editora do Conhecimento. 2008.

ORTIZ, Renato. A morte branca do feiticeiro negro: umbanda e sociedade brasileira. 2 ed. Petrópolis: Vozes. 1978.

PALMIÉ, Stephen. The Cultural Work of Yoruba Globalization. In: Christianity and Social Change in Africa: Essay in Honor of J.D.Y. Peel, Toyin Falola (Org.). Durham, NC: Carolina Academic Press, p. 43-81. 2005. PARÉS, Luis Nicolau. "The "Nagôization Process in Bahian Candomblé." In: The Yoruba Diaspora in the Atlantic World. CHILDS, Matt D.; FALOLA, Toyin (Orgs.). Bloomington e Indianapolis: Indiana University Press, p. 185-208. 2004.

- A formação do candomblé: história e ritual da nação jeje na Bahia. 2a ed. Campinas: Editora Unicamp. 2007.

PORTERFIELD, Amanda. Modern Christianity to 1900. Minneapolis: Fortress Press. 2007. 
PRANDI, Reginaldo. Referências sociais das religiōes afro-brasileiras: sincretismo, branqueamento, africanização. In: Faces da tradição afrobrasileiro: religiosidade, sincretismo, anti-sincretismo, reafricanização, práticas terapêuticas, etnobotánica e comida. CAROSO, Carlos; BACELAR, Jeferson (Orgs.). Rio de Janeiro/Salvador: Pallas/CNPq. 2006.

PYE, Michael. Syncretism and Ambiguity. Numen [Leiden] 18/2: p. 8393. 1971.

RAMOS, Arthur. As culturas negras no novo mundo. 4 ed. São Paulo: Companhia Editora Nacional. 1935.

. O negro brasileiro. 10 vol. Etnografia religiosa. 5 a ed. Rio de Janeiro: Graphia Editorial. 1934.

RITZER, George. The McDonaldization of Society 6. 6a ed. London e Thousand Oaks: SAGE. 1993.

ROBERTSON, Roland. Globalization: Social Theory and Global Culture. London e Thousand Oaks: SAGE. 1992.

. Glocalization: Time-Space and Homogeneity-Heterogeneity. In: Global Modernities. FEATHERSTONE, Mika; LASH, Scott; ROBERTSON, Roland (Orgs.). London: Sage, p. 25-44. 1995.

. Globalization Theory 2000+: Major Problematics. In: Handbook of Social Theory. RITZER, George; SMART, Barry (Orgs.). London e Thousand Oaks: SAGE, p. 458-471. 2001.

RODRIGUES, Raimundo Nina. O animismo fetichista dos negros bahianos. Rio de Janeiro: Civilização Brasileira. 1900.

ROHDE, Bruno Faria. Umbanda, uma religião que não nasceu: breves considerações sobre uma tendência dominante na interpretação do universo umbandista. Revista de Estudos da Religião (Rever) 9/1: p. 77-96. 2009.

SÁ JUNIOR, Mario Teixeira de. A invenção da alva nação umbandista: a relação entre a produção historiográfica brasileira e a sua influência na 
produção dos intelectuais da Umbanda (1840-1960). Universidade Federal de Mato Grosso do Sul. 2004.

SAHLINS, Marshall. Two or Three Things that I Know about Culture. The Journal of the Royal Anthropological Institute 5/3: p. 399-421. 1999.

SELKA, Stephen. Mediated Authenticity: Tradition, Modernity, and Postmodernity in Brazilian Candomblé. Nova Religio: The Journal of Alternative and Emergent Religions 11/1: p. 5-30. 2007.

SILVA, Vagner Gonçalves da. Reafricanização e Sincretismo: Interpretações Acadêmicas e Experiências Religiosas. In: Faces da Tradição Afro-Brasileira. CAROSO, Carlos; BACELAR, Jeferson (Orgs.). Rio de Janeiro/Salvador: Pallas/CEAO, p. 149-157. 1999.

. Candomblé e Umbanda: Caminhos da devoção brasileira. 2a ed. São Paulo: Selo Negro Edições. 2005.

STEWART, Charles. Syncretism and its Synonyms: Reflections on Cultural Mixture. Diacritics 29/3: p. 40-62. 1999.

. Relocating Syncretism in Social Science Discourse. In: Syncretism in Religion: A Reader. LEOPOLD, Anita M.; JENSEN, Jeppe S.; CAROSO, Carlos; BACELAR, Jeferson (Orgs.). London: Equinox, p. 264-285. 2004.

STEWART, Charles; SHAW, Rosalind. Syncretism/anti-Syncretism: The Politics of Religious Synthesis. London e New York: Routledge. 1994.

SWEET, James H. Recreating Africa: Culture, Kinship, and Religion in the African-Portuguese World, 1441-1770. Chapel Hill University of North Carolina Press. 2003.

TEIXEIRA, Maria Lina Leão. Candomblé e a (re)invenção de tradições. In: Faces da tradição afro-brasileiro: religiosidade, sincretismo, anti-sincretismo, reafricanização, práticas terapêuticas, etnobotánica e comida. CAROSO, Carlos; BACELAR, Jeferson (Orgs.). Rio de Janeiro/Salvador: Pallas/CNPq. 2006. 
THERBORN, Göran. Entangled Modernities. European Journal of Social Theory 6/3: p. 293-305. 2003.

USARSKI, Frank. (Re)Making Tradition in an International Tibetan Buddhist Movement: A Lesson from Lama Gangchen and Lama Michel. In: Historicizing "Tradition" in the Study of Religion. ENGLER, Steven; GRIEVE, Gregory Price (Orgs.). Berlin e New York: Walter DeGruyter, p. 345-56. 2005.

VARELLA, João Sebastião das Chagas. n.d. Manual do filho de santo. 3a ed. Rio de Janeiro: Editora Espiritualista.

VERGER, Pierre F. Dieux d'Afrique. Culte des Orishas et Vodouns à l'ancienne Côte des Esclaves en Afrique et à Bahia, la Baie de Tous les Saints au Brésil. Paris: Paul Hartmann. 1954.

WADE, Peter. Rethinking Mestizaje: Ideology and Lived Experience. Journal of Latin American Studies 37/2: p. 239-57. 2005. 